\title{
Front Matter: Volume 12078
}

, "Front Matter: Volume 12078," Proc. SPIE 12078, International Optical Design Conference 2021, 1207801 (6 December 2021); doi:

$10.1117 / 12.2603593$ SPIE. Event: International Optical Design Conference - IODC 2021, 2021, Online 


\section{PROCEEDINGS OF SPIE}

\section{International Optical Design Conference 2021}

Peter P. Clark

Richard N. Pfisterer

Henning Rehn

Simon Thibault

Editors

27 June - 1 July 2021

Washington, DC, United States

Organized by

Optica (formerly OSA), the Society Advancing Optics and Photonics Worldwide

Published by

SPIE

Volume 12078 
The papers in this volume were part of the technical conference cited on the cover and title page. Papers were selected and subject to review by the editors and conference program committee. Some conference presentations may not be available for publication. Additional papers and presentation recordings may be available online in the SPIE Digital Library at SPIEDigitalLibrary.org.

The papers reflect the work and thoughts of the authors and are published herein as submitted. The publisher is not responsible for the validity of the information or for any outcomes resulting from reliance thereon.

Please use the following format to cite material from these proceedings:

Author(s), "Title of Paper," in International Optical Design Conference 2021, edited by Peter P. Clark, Richard N. Pfisterer, Henning Rehn, Simon Thibault, Proc. of SPIE 12078, Seven-digit Article CID Number (DD/MM/YYYY); (DOI URL).

ISSN: 0277-786X

ISSN: 1996-756X (electronic)

ISBN: 9781510650305

ISBN: 9781510650312 (electronic)

Published by

SPIE

P.O. Box 10, Bellingham, Washington 98227-0010 USA

Telephone +1 3606763290 (Pacific Time)

SPIE.org

Copyright @ 2021 Society of Photo-Optical Instrumentation Engineers (SPIE).

Copying of material in this book for internal or personal use, or for the internal or personal use of specific clients, beyond the fair use provisions granted by the U.S. Copyright Law is authorized by SPIE subject to payment of fees. To obtain permission to use and share articles in this volume, visit Copyright Clearance Center at copyright.com. Other copying for republication, resale, advertising or promotion, or any form of systematic or multiple reproduction of any material in this book is prohibited except with permission in writing from the publisher.

Printed in the United States of America by Curran Associates, Inc., under license from SPIE.

Publication of record for individual papers is online in the SPIE Digital Library.

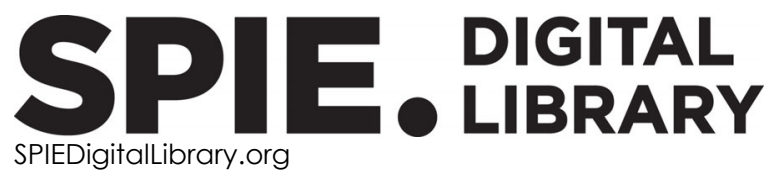

Paper Numbering: A unique citation identifier (CID) number is assigned to each article in the Proceedings of SPIE at the time of publication. Utilization of CIDs allows articles to be fully citable as soon as they are published online, and connects the same identifier to all online and print versions of the publication. SPIE uses a seven-digit CID article numbering system structured as follows:

- The first five digits correspond to the SPIE volume number.

- The last two digits indicate publication order within the volume using a Base 36 numbering system employing both numerals and letters. These two-number sets start with 00, 01, 02, 03, 04, 05, 06, 07, 08, 09, 0A, OB ... 0Z, followed by 10-1Z, 20-2Z, etc. The CID Number appears on each page of the manuscript. 


\title{
Contents
}

\author{
ix In memoriums \\ xvii Introduction \\ xxi Conference Committees
}

TOOLS AND METHODS IN LENS DESIGN I

1207802 Exploring the limits of CLOVER: a multichannel optics for VR and MR (Invited Paper) [12078-1]

1207803 The general equation of the stigmatic lenses: its history and what we have learned from it (Invited Paper) [12078-2]

1207804 Device for generating modulated Poincaré beams [12078-3]

1207805 Design of photonic nanojets on a silicon chip [12078-4]

OPTICAL DESIGN \& METHOD I

1207806 Hyper-aspheroidal surfaces: two approaches (Invited Paper) [12078-5]

$1207807 \quad$ New surface contributions for higher order color aberrations and chromatic variations of Seidel aberrations [12078-6]

$1207809 \quad$ Learning lens design from Rudolf Kingslake [12078-8]

12078 OA Laser scanning microscope with large field and high NA [12078-9]

OPTICAL DESIGN AND METHOD II

12078 OC Optical design of the Mastcam-Z lenses [12078-11]

12078 OE Optical considerations for design of surface disinfection devices based on UV-C LEDs [12078-13]

12078 OF Standards developed by National Institute of Standards and Technology for performance evaluation of optical medical imaging devices [12078-14] 
12078 OG Progress in aberration theory for freeform off-axis mirror systems (Invited Paper) [12078-15]

JOINT FREEFORM AND IODC II

$12078 \mathrm{OH} \quad$ Automatic obscuration elimination for off-axis mirror systems without plane of symmetry [12078-16]

12078 Ol Tunable LED-based illuminator using freeform arrays [12078-17]

\section{ADVANCED SYSTEMS AND HISTORY}

12078 0J Projection optical system with a pixelated $\mu$ LED source for automotive applications [12078-18]

12078 OK How to replace diffractive optical elements for color correction by refractive lenses from specific materials [12078-19]

12078 OL Optical glass selection for colour corrected broad band instrumentation: an overview [12078-20]

12078 OM Wafer-level curved sensor manufacturing process for enhanced optical system designs [12078-21]

12078 ON Design and replication of a six-channel foveated imaging system [12078-22]

1207800 Resolution enhancement of low-NA objectives in confocal fluorescence microscopy by diffractive lens arrays [12078-23]

12078 OP A perfect lens design hiding in plain sight for 167 years [12078-24]

$120780 Q \quad$ Panoramic lens an historical perspective: from sky lens to consumer wide angle freeform optics [12078-25]

\section{TOOLS AND METHODS IN LENS DESIGN II}

12078 OS Grating lobe suppression for the next generation Arecibo Telescope concept [12078-27]

12078 OT Multispectral IR imaging systems [12078-28]

12078 OU Abstract spaces, mappings and geometry in the study of optical systems (Invited Paper) [12078-29]

12078 OV Some lens structural performance displays [12078-30]

iv 
DIFFRACTIVE, GRADED-INDEX AND DISPLAY

12078 OW Proposed syllabus for augmented reality display waveguide design course (Invited Paper) [12078-31]

12078 0X Design of multi-order diffractive lens telescope for broadband application [12078-32]

12078 OY Theory of color correction in high-harmonic diffractive lenses (Invited Paper) [12078-33]

$120780 Z$ Material optimization in the design of broadband gradient-index optics [12078-34]

1207810 Diffractive multifocal lens analysis using complex Fourier series [12078-35]

$1207811 \quad$ Multilayer polymer GRIN singlets: manufacturing and performance [12078-36]

\section{ILLUMINATION DESIGN AND METHODS I}

1207812 Compound surface descriptions in illumination design [12078-37]

$1207813 \quad$ Light shaping with micro-optical irregular fly's eye condensers [12078-38]

1207814 A unusual zoom design for a variable edge beam [12078-39]

1207815 DC two-photon absorption signal offset and intensity autocorrelation amplitude comparison in the femtosecond pulse focusing of lenses with spherical aberration [12078-40]

1207816 Designing afocal achromatic doublet lenses [12078-41]

1207817 The era of computational lens design [12078-42]

\section{ILLUMINATION DESIGN AND METHODS II}

$1207818 \quad$ Evolution of zoom lens optical design technology and manufacture [12078-43]

$120781 \mathrm{~A} \quad$ On the use of deep learning for lens design [12078-45]

12078 1B Robustness estimation of simple lens systems by machine learning [12078-46]

TOOLS AND METHODS IN LENS DESIGN III

$120781 \mathrm{C} \quad$ Surface slope error tolerances: applicable range of spatial frequencies (Invited Paper) [12078-47] 
12078 1D A new optical adjustment mechanism for riflescopes [12078-48]

12078 1E Parallax error in telescopic gun sights [12078-49]

12078 IF Representations of off-axis conics for lens design [12078-50]

$120781 \mathrm{G} \quad$ Image forming design and analysis using python [12078-51]

\section{ANALYSIS AND APPLICATIONS}

$12078 \mathrm{1H} \quad$ Aberration analysis of zoom lens system with freeform surface lenses using XY polynomial [12078-52]

$1207811 \quad$ Wide-angle stereoscopic optical system using ultrashort throw lenses with a catadioptric relay [12078-53]

$12078 \mathrm{lJ}$ Design of an ultra-broadband, wide-field-of-view push-broom imaging radiometer [12078-54]

$120781 \mathrm{~K} \quad$ Off-axis, reflective Schmidt telescope design for proton beam imaging system [12078-55]

$120781 \mathrm{~L} \quad$ A novel design freeform reflector application applied to natural light illumination system [12078-56]

JOINT FREEFORM AND IODC III

12078 IM Aberration-based design example for freeform optical designs with base off-axis conics [12078-57]

JOINT FREEFORM AND IODC IV

$120781 \mathrm{~N} \quad$ Specification sweep for three-mirror freeform imagers [12078-58]

$1207810 \quad$ Lens design optimization by back-propagation [12078-59]

12078 IP Experimental investigation of third-order binodal astigmatism in Nodal Aberration Theory (NAT) with a Cassegrain system [12078-60]

$120781 Q \quad$ Optical design of an off-axis four-mirror objective system (OFOS) for a thermal camera [12078-61]

12078 IR Evaluating ophthalmic progressive addition lens designs with freeform surfaces and gradient index optics [12078-62]

12078 1S Design of annular folded lenses using freeform gradient-index optics [12078-63] 
12078 IT Design of a freeform refractive surface with reflection loss for illumination [12078-64]

$120781 \mathrm{U} \quad$ All-spherical wide-field camera [12078-65]

LENS DESIGN WITH FLAT OPTICAL AND METASURFACE COMPONENTS (JOINT FLAT OPTICS AND IODC)

12078 IW Toward hybrid refractive and metalens design [12078-68]

12078 IY Highly-efficient flat-optics inverse design platform via fast trained neural predictors [12078-70]

IODC 2021 OPTICAL DESIGN CHALLENGES

$120781 Z$ IODC 2021 illumination design problem: the curse of Prince Lambert (Invited Paper) [12078-71]

1207820 The 2021 IODC lens design problem: the down under lens (Invited Paper) [12078-72] 
Proc. of SPIE Vol. 12078 1207801-8

Downloaded From: https://www.spiedigitallibrary.org/conference-proceedings-of-spie on 25 Apr 2023 Terms of Use: https://www.spiedigitallibrary.org/terms-of-use 


\section{Erwin Delano}

1916-2019

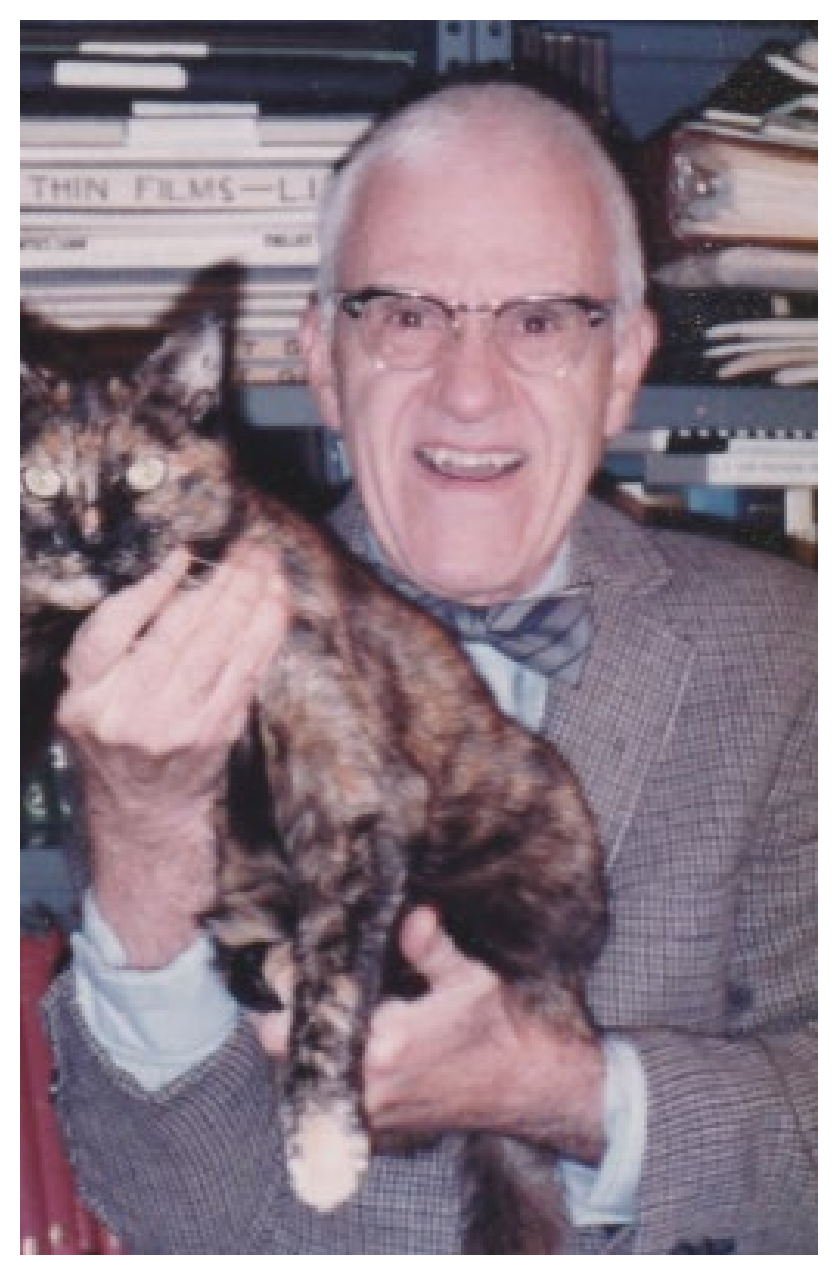

Erwin Delano passed away on June 16, 2019. He is largely remembered for his development of the $y \bar{y}$ diagram, widely recognized as a powerful optical design and layout tool.

Having training in Japanese, he served in the occupation force in Japan in WWII. Upon returning, he received his bachelor's degree from Yale under the GI bill, and began working for Bausch and Lomb in Rochester NY, where he designed the CinemaScope anamorphic lens for $20^{\text {th }}$ Century Studios.

In 1963 he published his seminal paper where he introduced his novel diagram which is still called either the Delano diagram or the y y diagram. He received his $\mathrm{Ph} . \mathrm{D}$. in 1966 from the University of Rochester and spend the next 26 years teaching physics and astronomy at St. Fisher College in Rochester. 
His y y diagram technique has been widely embraced by optical designers for a large variety of applications: first-order optical system layout (López-López, Shack, Hayford, etc), zoom lens design (Besenmatter), third-order design (Powell, Besenmatter), displays (Ames, Zeng), gradient optics design (Harrigan, Loce, Rogers) and laser system design (Kessler, Menard, Zhang), among others.

He also published on the aberration theory of Fresnel lenses. 


\section{Robert E. Fischer}

1943-2020

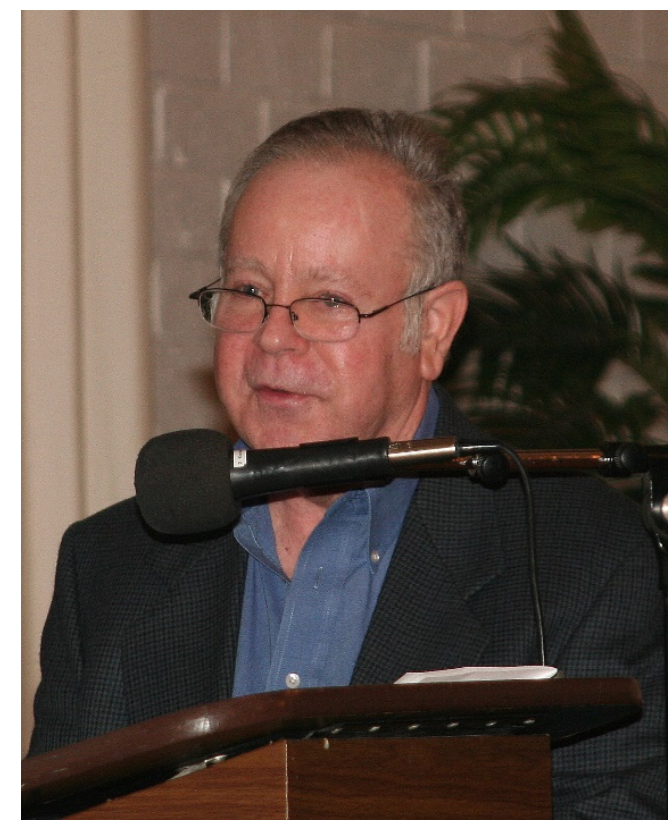

SPIE Fellow Robert E. "Bob" Fischer passed away in August of 2020 at the age of 77.

Bob received a BS and MS in optics from the University of Rochester. Prior to founding Optics 1 in 1987, he was assistant manager of the Lens Design Section at ITEK Corp. and then chief scientist at Hughes Aircraft Company.

Bob's technical interests were in optical system design and engineering, in particular lens design. He was also interested in optical component and system manufacturing, assembly, and testing.

He contributed both financial resources and time to the optics community. He developed and taught numerous courses and co-authored the book, Optical Systems Design with Biljana Tadic-Galeb and Paul Yoder. Bob also gave several talks for the Optical Society of Southern California.

A long-time SPIE Member, Bob served SPIE in a variety of roles including treasurer, editor of $O E R e$ ports, chair of multiple committees, and as SPIE president in 1984. Fischer was awarded the Albert M. Pezzuto Award in 1986, and the SPIE Gold Medal in 2000.

Bob's memorable and entertaining presentations at conferences were noted for their insights regarding optical aberrations, a list of Bloopers and Blunders in Optics, vacation photos, and magic tricks. 
Proc. of SPIE Vol. 12078 1207801-12 Downloaded From: https://www.spiedigitallibrary.org/conference-proceedings-of-spie on 25 Apr 2023
Terms of Use: https://www.spiedigitallibrary.org/terms-of-use 


\title{
Thomas I. Harris
}

\author{
1930-2021
}

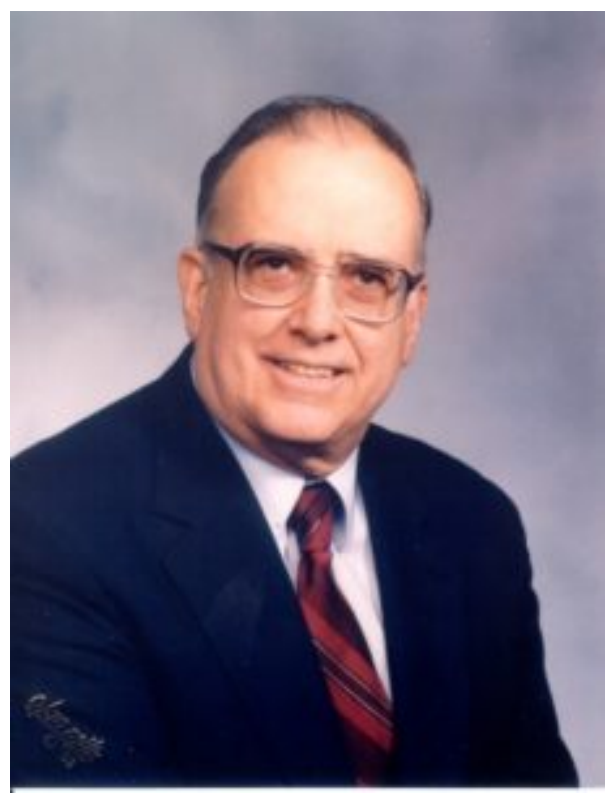

Long recognized by colleagues and the optics community for his many contributions to the field, Tom Harris passed away on January 16, 2021, at the age of 90.

Tom grew up in Wisconsin and received a B.S. degree in Physics from the University of Wisconsin in 1952. He received an M.S. degree in Optics and Physics at the University of Rochester, where he studied with renowned professors Rudolph Kingslake and Robert Hopkins.

In 1953, Tom started his career at the Bell \& Howell Company in Chicago testing lenses, filters, and optical materials. Within a year, he programmed accounting machines to perform ray tracing for lenses and researched early methods of lens design optimization. This work would form the foundation for Harris' later success co-creating CODE V.

In 1963, Tom founded Optical Research Associates (ORA) - now the Optical Solutions Group at Synopsys. He served as President of ORA from 1963 - 1991 and was Chairman and CEO from 1991 - 2000. Harris retired as CEO in 2000, but he continued his work as Chairman of the ORA Board of Directors until 2006.

In addition to developing improved automatic optical design methods, Tom contributed to a wide range of innovations in global optimization techniques, tolerancing methods, environmental and narcissus calculations, and modeling of partial dispersions of optical glasses. He was an early contributor to embedding optical engineering expertise in CODE V to help guide users in their design work. 
Tom was an active volunteer in the optics community. He served as Treasurer of SPIE for 11 years and was a longtime member of the Optical Society of America (OSA), where he served on the Finance Council and Technical Coordinating Committee.

Tom was a Fellow of both SPIE and OSA. In 1998, he received SPIE's Gold Medal for lifetime achievement in lens design as well as continuous service to optical engineering. He also received the OSA Joseph Fraunhofer Award in 1990, SPIE's Presidents Award in 1992, and was corecipient with Darryl Gustafson of the SPIE Technology Achievement Award for the development of CODE V in 1984. In 1995, he was made a Life Member of SPIE. Tom held five U.S. patents in the field of optics and published numerous technical papers. 


\section{Roland V. Shack}

1927-2019

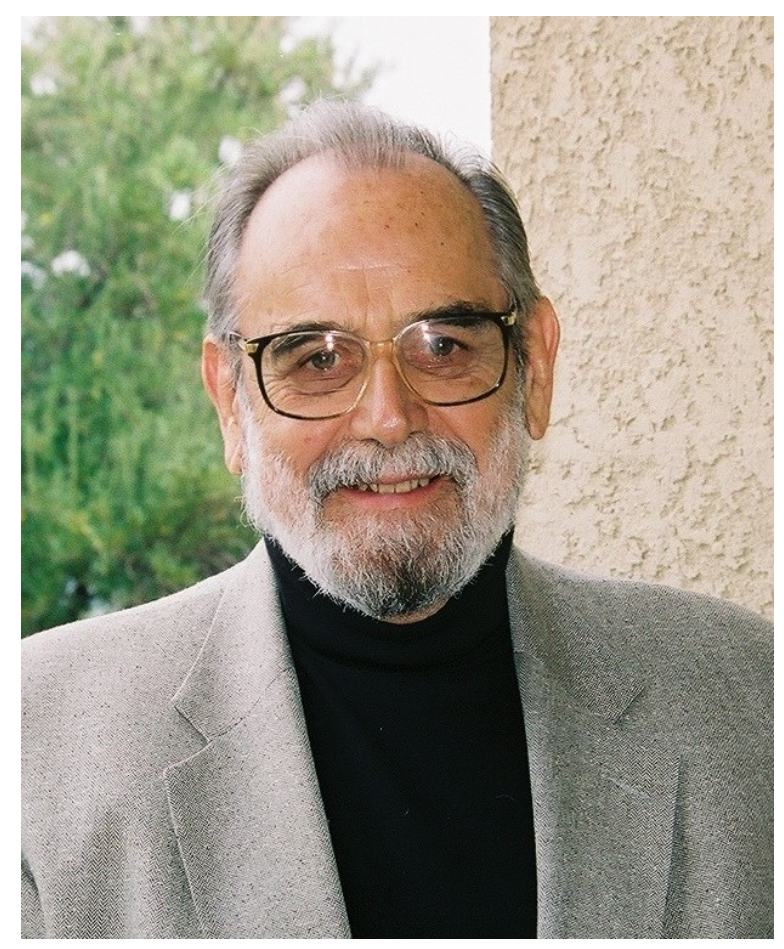

Professor emeritus of Optical Sciences at the University of Arizona's Wyant College of Optical Sciences, Roland Shack passed away on October 18, 2019 at the age of 92. Roland's multiple talents and contributions to the field of optics are legendary. His name can be found many scientific publications, his Shack-Hartmann Sensor and the Shack Cube Interferometer are "household words", and he was the driving force behind the development of nodal aberration theory. But, for many, Roland's dedication to his students and the learning process is considered one of his greatest influences on the optics community.

Roland was born in Chicago, Illinois, USA on 15 January 1927. His family moved to Washington D.C., and later graduated from Washington \& Lee High School in Arlington, Virginia in 1944. At this time, he received a Bausch \& Lomb Honorary Science Award and a full scholarship to Massachusetts Institute of Technology, but enlisted in the army instead of attending college. He was able to complete some education during his two years of service, and when discharged tried to return to MIT. However, due to the high number of returning veterans, the wait to enroll was too long for Roland, who ultimately decided to attend the University of Maryland, College Park to study physics. He earned a Bachelor of Science in Physics there in 1949. Two years later, he earned a Bachelor of Arts in Fine Arts from American University in Washington, D.C. 
His professional career began at the National Bureau of Standards. In 1957, he moved to Norwalk, Connecticut to work for the Perkin-Elmer Corporation. After three years, he was encouraged to pursue a Ph.D., which he did. He moved his family to the United Kingdom where he studied at Imperial College London. He completed his Ph.D. in 1965 and returned to PerkinElmer in the US. As one of the very first faculty members hired by Adel Meinel, he began his professorship at the University of Arizona in the fall of 1965. In 1989, he started to expand the undergraduate offerings at the Optical Sciences Center significantly. Roland remained in this role until 1973.

Roland mentored an astonishing number of students, many of whom have gone onto distinguished careers in optics. This includes not only the 46 students for whom he was their MS or $\mathrm{PhD}$ advisor (and that is a pretty impressive list, if you look at the names) but also those who studied under him.

Shack received extensive recognition for his significant contributions, including the 1998 SPIE A.E. Conrady Award in Optical Engineering, the 2004 SPIE Gold Medal, and the 2003 OSA David Richardson Medal. He was a Fellow of OSA and SPIE. 


\section{Introduction}

The International Optical Design Conference 2021 (IODC 2021) continues a distinguished fifty-five year tradition of conferences dedicated to the art and science of optical design: Rochester NY (1966), Haverford College PA (1975), Mills College CA (1980), Cherry Hill NJ (1985), Monterey CA (1990), Rochester NY (1994), Kona HI (1998), Tucson AZ (2002), Vancouver BC (2006), Jackson Hole WY (2010), Kona HI (2014) and Denver CO (2017). This Proceedings collects most of the work presented at IODC 2021 as published papers.

This was an unusual IODC. It was planned to be held in Providence, Rhode Island, June 27 - July 1, 2021, but the COVID-19 pandemic that began in early 2020 prevented us from holding an in-person meeting. It was decided to convert to an all-remote format over the same range of dates.

One of the great attractions of IODC is to catch up with colleagues from around the world and to have conversations about the latest developments in optical design. This opportunity was lost in 2021, and those who have been able to attend earlier IODCs sorely missed it. But the remote conference format did offer some unexpected benefits. People attended and presented without the need for travel, so IODC became more broadly accessible. There were recorded videos of the talks that attendees could review during the conference and for some time after. Those videos will be made available again to conference registrants by Optica (OSA) after they are saved in their database. We expect that papers that could not be included in this Proceedings will be available as videos.

IODC 2021 was co-located with three related topical meetings: Optical Fabrication and Testing (OF\&T), Freeform Optics, and Flat Optics: Components to Systems. OF\&T has long been a partner with IODC, Freeform joined IODC in 2017, and Flat Optics was new in 2021.

At IODC 2021, three Plenary talks were presented, representing each of the colocated conferences. Dr. Joseph Howard (NASA Goddard) spoke on "Current and Future NASA Space Telescopes", commenting on the "golden age of astronomy" where NASA space telescopes are expected to contribute to our rapidly growing understanding of the universe. Dr. James Wyant (University of Arizona) gave a talk on "The History of Interferometric Optical Testing", drawing from his extensive experience as founder of WYKO and 4D Technology Corporation. Mr. Julius Muschaweck (JMO Illumination Optics) presented a talk entitled "Freeform Optics for Illumination and Imaging: Quite a Ride, and Still a Long Way to Go", pointing out that, despite advances in nodal aberration theory, 
key pieces of theoretical understanding, accessible design methods, and reliable yet affordable manufacturing processes still wait to be discovered.

In order to best accommodate presenters in different time zones from all over the world, talks were scheduled throughout the day Monday through Thursday. A total of over 70 invited and contributed papers were given.

Several awards were presented: The Kevin P. Thompson Optical Design Innovator Award was awarded to Rengmao Wu from Zhejiang University, China, for achievements in theory and computational methods for freeform illuminations optics. The Michael Kidger Memorial Scholarship was awarded to Geoffroi Côté, a Ph.D. student at Université Laval working under Professors Simon Thibault and Jean-François Lalonde.

Lens designers and illumination system designers enthusiastically participated in the 2021 Lens Design and Illumination Design Problems. The results were presented in a special session on Tuesday and are published in this Proceedings:

The Lens Design Problem, proposed by Dave Shafer, was entitled "The Down Under Lens" where the designer had to design a $100 \mathrm{~mm}$ focal length lens where, if the lens were flipped end-to-end but the radii were not reversed in sign, the lens had to perform the same as in its original form. Damien Gawron from Safran Electronics and Defense (France) won the lens design competition with a merit function (pupil diameter in $\mathrm{mm} \times$ semi-field angle in degrees) of 17,857; after the competition he submitted a revision that attained a perfect merit function of 18,000 !

The Illumination Design Problem, developed by the team of Bill Cassarly, Julius Muschaweck, Henning Rehn and John Koshel, was entitled "The Curse of Prince Lambert" where "illumination wizards and apprentices" working with a "diamond scepter" $5 \mathrm{~mm}$ in diameter and $200 \mathrm{~mm}$ long and a "crystal ball" $200 \mathrm{~mm}$ in diameter made of "noble glass" had to reverse the curse and "unscramble Prince Lambert so that he can return to his full, glorious power" (i.e., maximize power on $1 \times 1 \mathrm{~mm}^{2}$ receiver). The team published an extremely clever story line/problem writeup with an Old English flair. Jake Jacobsen from Synopsys submitted the winning solution composed of a cone lens assembly, a prism array, a nineelement rocket array and finally a projector lens.

At the beginning of the Design Problem event, we paid tribute to four truly distinguished colleagues and fellow researchers, lens designers, and software developers who had passed away since IODC 2017: Erwin Delano, Robert Fischer (Chair of IODC 1980), Thomas Harris, and Roland Shack. 
We're grateful to the following organizations for their support as co-sponsors of the conference: Airy Optics, American Elements, Carl Zeiss Jena GmbH, Jenoptik, Lambda Research Corporation, Optical Systems Design, LLC, Optikos Corporation, and Synopsys, Inc.

It has been on honor and privilege to serve as chairs for the IODC 2O21. However, the success of IODC is the result of the combined efforts of so many people and organizations that it is impossible to give credit to everyone. Special thanks go to the members of the program committee and their respective companies and institutions for their support of the IODC. We'd like to acknowledge the efforts of Groot Gregory for managing the IODC website www.iodc.info for us as a conduit of information specific to the conference. Finally, we are especially grateful to the teams at Optica (OSA) and SPIE for supporting this (and previous) IODCs with their organizational and management skills and help in preparing this proceedings volume.

Ultimately the success of any conference depends upon participation of the attendees, and so we thank everyone who took time out of busy lives to be part of IODC 2021. Your experiences and insights, presentations, side discussions, and networking contributed to the richness of the IODC 2021. We look forward to sharing future International Optical Design conferences with you.

The next IODC is already being planned to happen sooner than usual, in the summer of 2023, when (we hope!) the pandemic will be completely under control. It will be held both in-person and remote, and so we expect to have the advantages of both formats. The location and exact dates of IODC 2023 are to be determined, as of this writing.

\author{
Simon Thibault \\ Henning Rehn \\ Peter P. Clark \\ Richard N. Pfisterer
}


Proc. of SPIE Vol. 12078 1207801-20 Downloaded From: https://www.spiedigitallibrary.org/conference-proceedings-of-spie on 25 Apr 2023
Terms of Use: https://www.spiedigitallibrary.org/terms-of-use 


\section{Conference Committee}

\section{Conference Chairs}

Simon Thibault, Université Laval (Canada)

Henning Rehn, FISBA (Germany)

Peter P. Clark, retired (United States)

Richard N. Pfisterer, Photon Engineering, LLC (United States)

\section{Program Committee}

Dave Aikens, Savvy Optics Corporation (United States)

Miguel A. Alonso, University of Rochester (United States)

Aaron Baver, University of Rochester (United States)

Julie Bentley, University of Rochester (United States)

Peter Brick, OSRAM Opto Semiconductors GmbH (Germany)

Thomas Brown, University of Rochester (United States)

William Cassarly, Synopsys, Inc (United States)

Peter Clark, retired (United States)

Josh Cobb, Corning Tropel (United States)

Jasmin Cote, Side by Side Optical Engineering (Canada)

Christopher Dainty, Xperi FotoNation (Ireland)

Rufino Diaz-Uribe, Universidad Nacional Autonoma de Mexico (Mexico)

Kai Engelhardt, Heptagon (consultant) (Germany)

Alexander Epple, Carl Zeiss AG (Germany)

Stephen D Fantone, Optikos (United States)

Greg Forbes, Scisense Consulting (Australia)

Florian Fournier, Apple (United States)

Edward Freniere, Lambda Research Corporation (United States)

Kyle Fuerschbach, Sandia National Labs (United States)

Groot Gregory, Synopsys, Inc (United States)

John Greivenkamp, University of Arizona (United States)

Herbert Gross, Friedrich Schiller University Jena (Germany)

Anurag Gupta, Nest (United States)

Lakshminarayan Hazra, University of Calcutta (India)

Michael Hayford, retired (United States)

Alois Herkommer, University of Stuttgart (Germany)

Eric Herman, Zygo (United States)

Joe Howard, NASA (United States)

Boyd Hunter, Corning (United States)

Richard Juergens, II-VI (United States)

Norbert Kerwien, Carl Zeiss AG (Germany)

John Koshel, University of Arizona (United States) 
Jay Kumler, JENOPTIK Optical Systems LLC (United States)

Scott A Lerner, Synopsys, Inc. (United States)

Paul Manhart, Mission Support and Test Services, LLC (United States)

Benjamin Masella, Optikos (United States)

Jim McGuire, Jet Propulsion Laboratory (United States)

Paul Michaloski, Corning Advanced Optics (United States)

Michael Missig, Bausch \& Lomb, Inc (United States)

Pantazis Mouroulis, Jet Propulsion Laboratory (United States)

Julius Muschaweck, JMO Illumination Optics (Germany)

lain Neil, Scotoptix (Switzerland)

Thomas Nobis, Carl Zeiss AG (Germany)

Matt Novak, Synopsys, Inc. (United States)

Richard Pfisterer, Photon Engineering, LLC (United States)

Henning Rehn, FISBA (Germany)

Jannick Rolland, University of Rochester (United States)

Martha Rosete-Aguilar, Universidad Nacional Autonoma de Mexico (Mexico)

Mark Sanson, Corning (United States)

Jose Sasian, University of Arizona (United States)

Vesselin Shaoulov, University of Central Florida (United States)

Dan Smith, Nikon Research Corporation of America (United States)

Harvey Spencer, DRS Technologies (United States)

Bryan Stone, Synopsys, Inc (United States)

Simon Thibault, Université Laval (Canada)

Andreas Timinger, Lumileds Germany GmbH (Germany)

Kristina Uhlendorf, Sypro Optics (Germany)

Sergio Vázquez y Montiel, Universidad Politecnica de Tulancingo (Mexico)

Anthony Visconti, Optikos (United States)

Yongtian Wang, Beijing Institute of Technology (China)

Akira Yabe, Akira Yabe Lens Design (Japan)

Takanori Yamanashi, Theta Optical LLC (United States)

Richie Youngworth, Riyo LLC (United States)

\section{Lens Design Problem Committee}

Rick Juergens, II-VI (United States)

David Shafer, David Shafer Optical Design (United States)

Thomas Nobis, Carl Zeiss AG (Germany)

\section{Illumination Design Problem Committee}

William Cassarly, Synopsys, Inc. (United States)

Julius Muschaweck, JMO Illumination Optics (Germany)

Henning Rehn, FISBA (Germany)

John Koshel, University of Arizona (United States) 